\title{
6 .

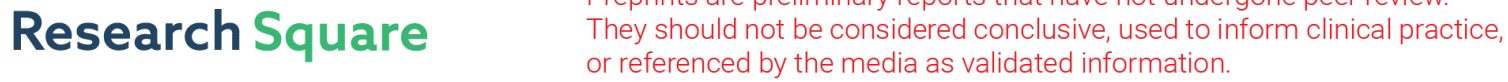 \\ VDAC1 and RhoA in Plasma Exosomes Influence the Severity of Adolescent Idiopathic Scoliosis
}

\section{Huizhen Li}

Shanghai Jiaotong University School of Medicine Xinhua Hospital

\section{Nan Shen}

Shanghai Childrens Medical Center Affiliated to Shanghai Jiaotong University School of Medicine

\section{Lin Mao}

Shanghai Jiaotong University School of Medicine Xinhua Hospital

\section{Meijia Chen}

The Second Rehabilitation Hospital of Shanghai

\section{Xuan Zhou}

Shanghai Jiaotong University School of Medicine Xinhua Hospital

\section{Nan Chen}

Shanghai Jiaotong University School of Medicine Xinhua Hospital

\section{Xin Li}

Shanghai Jiaotong University School of Medicine Xinhua Hospital

\section{Juping Liang}

Shanghai Jiaotong University School of Medicine Xinhua Hospital

\section{Yuqi Yang}

Shanghai University of Medicine and Health Sciences

\section{Qing Du ( $\sim$ duqing@xinhuamed.com.cn )}

Xinhua Hospital Affiliated to Shanghai Jiao Tong University School of Medicine

\section{Research article}

Keywords: Adolescent idiopathic scoliosis (AIS), voltage-dependent anion-selective channel 1 (VDAC1), rhodopsin A (RhoA), proteomics, biomarker

Posted Date: September 18th, 2020

DOI: https://doi.org/10.21203/rs.3.rs-65485/v1

License: (9) (1) This work is licensed under a Creative Commons Attribution 4.0 International License. Read Full License 


\section{Abstract}

Background: Adolescent idiopathic scoliosis (AIS) is the most common spine deformity, but biomarkers for its condition are lacking. Rhodopsin A (RhoA) and voltage-dependent anion-selective channel 1 (VDAC1) in plasma exosomes were defined as differentially expressed proteins between AIS patients and healthy controls. The purpose of this study was to assess exosomes as biomarkers for the occurrence and progression of AIS.

Methods $\llbracket$ We recruited 10 AIS patients and 8 healthy controls to detect expressed proteins from plasma by liquid chromatography coupled to tandem mass spectrometry. Plasma samples were analyzed by liquid chromatography coupled to tandem mass spectrometry (LC-MS/MS). Pathway analysis identified that the VDAC1 and RhoA proteins were alterations expressed in the AIS patients, with the most different alteration was found in extracellular exosomes. Ultracentrifugation was carried out to isolate exosomes from plasma. Verification of the most differentially expressed protein was accessed by Western blot analysis and bioinformatics analysis was performed to predict the pathway of it.

Results: 42 of significantly differentially expressed proteins were found in all subjects, and 17 proteins had significant difference. The differentially expressed proteins were enriched in plasma exosomes, and some proteins, such as FN1, were upregulated and others, such as VDAC1, RhoA and AHNAK, were downregulated in the AIS patients. Furthermore, ultracentrifugation was carried out to isolate exosomes from plasma, and RhoA and VDAC1 proteins in plasma exosomes were verified to downregulate by western blot. KEGG signaling pathways were used to predict potential pathways involved in the RhoA and VDAC1 proteins in the AIS patients. We found that the RhoA protein influences AIS probably through the chemokine signaling pathway, platelet activation and CAMP signaling pathway, and the VDAC1 protein is a key factor that participates in the necroptosis pathway, acting on the development of AIS.

Conclusions: Consequently, this study mapped a profile of plasma protein, found the differentially expressed protein in AIS, which indicating that plasma exosomes, as a novel biomarker with high specificity, could be associated with the severity of AIS.

\section{Background}

Adolescent idiopathic scoliosis (AIS) is defined as a lateral curvature of the spine with a Cobb angle of at least $10^{\circ[1]}$ and affects approximately $0.47-11.1 \%$ of the general population ${ }^{[2]}$. The reported prevalence was $1.8 \%\left[{ }^{[3]}\right.$. AIS is a highly heterogeneous condition, with some patients showing rapid progression ${ }^{[4]}$. This disease increases the risk of physical and mental symptoms, such as trunk deformity and pulmonary impairment ${ }^{[5,6]}$. Several previous studies failed to identify biomarkers of $\operatorname{AIS}^{[7,8]}$. Therefore, screening biomarkers that can be used in the early identification and diagnosis of AIS is important for monitoring curvature progression before skeletal maturation. 
Exosomes are $20-100 \mathrm{~nm}$ in size and are enveloped by a phospholipid membrane. These particles are produced by normal as well as malignant cells and are present in all human body fluids ${ }^{[9]}$. Exosomes are considered a biomarker for many diseases ${ }^{[10-14]}$. Similar to cells, exosomes are composed of lipid bilayers and contain many molecular components of cells, such as proteins, miRNAs, and DNA ${ }^{[15]}$. We used proteins to confirm the role of exosomes because they usually display a high purity ${ }^{[16]}$ and stable expression.

In this study, in order to investigate novel biomarkers of AIS, we used mass spectrometry (MS) to screen the differentially expressed plasma proteins between AIS patients and healthy controls, and the potential biomarkers of exosomal proteins in AIS patients were confirmed.

\section{Methods}

\section{Patients and clinical samples}

All the participants provided written informed consent. A total of 10 AIS patients and 8 matched healthy individuals with similar baselines (Table 1) were enrolled from the Xinhua Hospital affiliated with the Shanghai Jiaotong University School of Medicine from August 2017 to August 2018. According to The Scoliosis Research Society (SRS), all enrolled AIS patients were confirmed when the Cobb angle was $10^{\circ}$ or higher and axial rotation was observed by radiography and a physical examination. The study processes are shown in Fig. 1. 
Table 1

Clinical characteristic of the recruited subjects in clinical study.

\begin{tabular}{|lll|}
\hline Characteristics & \multicolumn{2}{l|}{ Groups } \\
\cline { 2 - 3 } & AlS $(\mathbf{N}=10)$ & Control(N=8) \\
\hline Age(year) & $13.60 \pm 1.17$ & $14.88 \pm 0.83$ \\
\hline Female(case) & $9(1)$ & $7(1)$ \\
\hline BMI(kg/m $\left.{ }^{2}\right)$ & $18.64 \pm 1.66$ & $19.31 \pm 1.99$ \\
\hline Menarche age (year) & $11.89 \pm 1.36$ & $12.2 \pm 0.76$ \\
\hline Cobb angle & & \\
\hline $10^{\circ}-50^{\circ}$ & 10 & - \\
\hline$\geq 50^{\circ}$ & 0 & - \\
\hline Risser & & \\
\hline $0-3$ & 7 & - \\
\hline $4-5$ & 3 & - \\
\hline Note: $B M l$, body mass index. & \\
\hline
\end{tabular}

Ten milliliters of venous blood were collected in EDTA anticoagulant tubes. Plasma was obtained after a 15 -min centrifugation at $300 \mathrm{~g}$ to remove the cells and a second 5-mi centrifugation at $1500 \mathrm{~g}$ to remove the remaining platelets and apoptotic bodies. The purified plasma samples were stored at $-80^{\circ} \mathrm{C}$ until further use.

\section{Isolation of the exosomes from the blood plasma with ultracentrifugation}

After centrifugation at $2,000 \mathrm{~g}$ and $12,000 \mathrm{~g}$ to remove the cells and cellular debris, the exosomal supernatant was centrifuged at $110,000 \mathrm{~g}$ for 2 hours to collect the exosomal fraction. Then, the suspension was filtered through a $0.22 \mu \mathrm{m}$ filter, centrifuged at 110,000 g for 70 min two times, and resuspended in PBS. All centrifugation steps were performed at $4{ }^{\circ} \mathrm{C}$.

\section{Flow cytometry and analysis of particle size}

To confirm the contents of the purified exosomes from the plasma samples, we used an Accuri C6 flow cytometer (BD Instruments) to detect CD63 and CD81 by flow cytometric analysis. The size distribution of both kinds of exosomes was evaluated with a Zetasizer Nano series-Nano-ZS (Malvern Instruments).

\section{Electron microscopy}


Fifty microliters of exosomal proteins was adsorbed by copper grids and fixed with $1 \%$ glutaraldehyde. After staining with $3 \%$ phosphotungstic acid solution, the grids and the samples were dried, and a JEM1230 system was used to image the exosome samples.

\section{LC-MS/MS}

Sample dilution buffer $(100 \mathrm{mM}, 10 \mathrm{mM}$ HEPES, $\mathrm{pH}=7.4)$ was added to the blood sample to remove the lipids, and then, cold ethanol solution was used to remove the peak components. Next, we enzymatically hydrolyzed the protein sample by TEAB solution containing trypsin. Then, label reagent was added to each tube, and the sample corresponding to each TMT color was recorded and mixed. The TMT-labeled peptide mixture was separated on an Agilent $1260 \mathrm{HPLC}$ system at a rate of $0.2 \mathrm{ml} / \mathrm{min}$ using a Water XBridge BEH130 C18 $3.5 \mu \mathrm{m}$ 2.1A $150 \mathrm{~mm}$ column, and the CBS-B programmed multifunctional automatic fraction collector (Huxi Instruments, Shanghai, China) for HPLC was used to collect the eluted peptides. A total of 28 fragments of each peptide mixture were collected, ligated to level 14 , dried and subjected to nano LC-MS/MS analysis. An Easy nano-LC (Thermo Fisher Scientific) system was inverted at a flow rate of $300 \mathrm{nl} / \mathrm{min}$ using a self-packing column (75 $\mu \mathrm{m} \AA \AA 2150 \mathrm{~mm} ; 3 \mu \mathrm{m}$ ReproSil-Pur C18 beads, $120 \AA$, Dr. Maisch GmbH, Ammerbuch, Germany) for high-performance liquid chromatography (RPHPLC) separation. The MS analysis detected the parameters of the 12 strongest ions and scanned the results by an Orbitrap analyzer.

\section{Western blotting}

Exosomal proteins $(15-20 \mu \mathrm{l}, 30 \mu \mathrm{g}$ ) were separated on $10 \%$ sodium dodecyl sulfate-polyacrylamide gel electrophoresis (SDS-PAGE) gels and transferred to polyvinylidene difluoride membranes (GE Healthcare). After the membranes were blocked with $5 \%$ nonfat milk in PBST buffer (PBS buffer containing $0.1 \%$ Tween-20), they incubated in anti-calnexin (1:1000, Abcam), anti-CD63 (1:4000, Abcam) and anti-TSG101 (1:4000, Abcam) antibodies for verified exosome-specific markers. Anti-voltage-dependent anion-selective channel 1 (VDAC1) (1:1000, Abcam), anti-rhodopsin (RhoA) (1:1000, Abcam), anti-AHNAK (1:2000, Abcam) and anti-fibronectin (FN1) $\left(1: 12000\right.$, Abcam) were incubated overnight at $4{ }^{\circ} \mathrm{C}$. Then, the membranes were washed and exposed to the corresponding secondary antibody-rabbit IgG HRP-linked antibody (1:2000, Cell Signaling) and mouse IgG HRP-linked antibody (1:2000, Cell Signaling)-for 1 hour at room temperature and washed 3 times for 15 min in wash buffer. Finally, we detected the protein bands with enhanced chemiluminescence reagent (Millipore) and imaged them with an ImageQuant LAS 4000 mini densitometer (GE Healthcare Life Sciences).

\section{Bioinformatics and statistical analyses}

Functional gene ontology enrichment analysis of biological processes, molecular functions, and cellular components was performed using DAVID Bioinformatics Resources version 6.7. The protein-protein interaction (PPI) network of differentially expressed proteins was analyzed by STRING. The PPI network was processed by Cytoscape software. The pathway network was further analyzed by Ingenuity Pathway Analysis (IPA). 
All statistical analyses were performed using SPSS 20.0 statistical software. Data are expressed as the mean \pm standard deviation. The Pearson correlation test was used for the correlation between the Cobb angle and the differentially expressed proteins. Any difference with a P value less than 0.05 after correction was considered significant.

\section{Results}

\section{Exosomes proteins were differentially expressed in the AIS patients and the controls}

After the exosomes were isolated from the plasma of the AIS patients and the controls, we performed MS to screen the differentially abundant proteins in the exosomes of the plasma samples from the AIS patients versus the healthy controls $\left(\log _{2}\right.$ ratio $>1.5$ or $\left.<-1.5\right)$. A total of 652 proteins were identified, and 626 proteins had quantitative information. Forty-two significantly differentially expressed proteins were found in the AIS group and the control group, and 17 proteins had values greater than 1.5 (Fig. 2A, B) (Table 2). 
Table 2

The characteristics of differential proteins (larger than 1.5).

\begin{tabular}{|c|c|c|c|}
\hline Proteins & Regulation & Position & Functions \\
\hline FN1 & $\begin{array}{l}\text { Up } \\
\text { regulation }\end{array}$ & $\begin{array}{l}\text { Extracellular } \\
\text { matrix }\end{array}$ & $\begin{array}{l}\text { Participate in cell adhesion, cell motility, } \\
\text { opsonization, wound healing, maintenance of cell } \\
\text { shape, osteoblast mineralization }\end{array}$ \\
\hline UCP3 & $\begin{array}{l}\text { Up } \\
\text { regulation }\end{array}$ & $\begin{array}{l}\text { Mitochondrion } \\
\text { inner membrane }\end{array}$ & $\begin{array}{l}\text { As a mitochondrial transporter proteins } \\
\text { participate in thermogenesis and energy balance }\end{array}$ \\
\hline $\begin{array}{l}\text { IGHV1OR15- } \\
9\end{array}$ & $\begin{array}{l}\text { Up } \\
\text { regulation }\end{array}$ & - & Immunoglobulin receptor binding \\
\hline IGHV1-69 & $\begin{array}{l}\text { Up } \\
\text { regulation }\end{array}$ & Cell membrane & Antigen recognition, immunoglobulins \\
\hline ISY1 & $\begin{array}{l}\text { Up } \\
\text { regulation }\end{array}$ & Nucleus & Component of the spliceosome \\
\hline IGKV1-33 & $\begin{array}{l}\text { Up } \\
\text { regulation }\end{array}$ & Cell membrane & Antigen recognition, immunoglobulins \\
\hline CELSR2 & $\begin{array}{l}\text { Up } \\
\text { regulation }\end{array}$ & $\begin{array}{l}\text { Cell membrane, } \\
\text { Cytosol }\end{array}$ & $\begin{array}{l}\text { Receptor in cell/cell signaling during nervous } \\
\text { system formation }\end{array}$ \\
\hline IGLV3-10 & $\begin{array}{l}\text { Up } \\
\text { regulation }\end{array}$ & Cell membrane & Antigen recognition, immunoglobulins \\
\hline IGHV1-3 & $\begin{array}{l}\text { Up } \\
\text { regulation }\end{array}$ & Cell membrane & Antigen recognition, immunoglobulins \\
\hline EN01 & $\begin{array}{l}\text { Down } \\
\text { regulation }\end{array}$ & $\begin{array}{l}\text { Cytoplasm, Cell } \\
\text { membrane }\end{array}$ & $\begin{array}{l}\text { Multifunctional enzyme, stimulates } \\
\text { immunoglobulin production, tumor suppressor }\end{array}$ \\
\hline CAPN1 & $\begin{array}{l}\text { Down } \\
\text { regulation }\end{array}$ & $\begin{array}{l}\text { Cytoplasm, Cell } \\
\text { membrane }\end{array}$ & $\begin{array}{l}\text { Catalyzes limited proteolysis of substrates } \\
\text { involved in cytoskeletal remodeling and signal } \\
\text { transduction }\end{array}$ \\
\hline IGF2R & $\begin{array}{l}\text { Down } \\
\text { regulation }\end{array}$ & $\begin{array}{l}\text { Lysosome } \\
\text { membrane }\end{array}$ & $\begin{array}{l}\text { Transport and involved in suppression of breast, } \\
\text { tumor and promyelocytic leukemia }\end{array}$ \\
\hline GDI2 & $\begin{array}{l}\text { Down } \\
\text { regulation }\end{array}$ & $\begin{array}{l}\text { Cytoplasm, } \\
\text { Membrane }\end{array}$ & Regulate the GDP/GTP exchange reaction \\
\hline HSPB1 & $\begin{array}{l}\text { Down } \\
\text { regulation }\end{array}$ & $\begin{array}{l}\text { Cytoplasm, } \\
\text { Nucleus }\end{array}$ & $\begin{array}{l}\text { Molecular chaperone, stress resistance and actin } \\
\text { organization, regulate numerous biological } \\
\text { processes }\end{array}$ \\
\hline IGHV3-13 & $\begin{array}{l}\text { Down } \\
\text { regulation }\end{array}$ & Cell membrane & Antigen recognition, immunoglobulins \\
\hline IGHV1-18 & $\begin{array}{l}\text { Down } \\
\text { regulation }\end{array}$ & Cell membrane & Antigen recognition, immunoglobulins \\
\hline LRG1 & $\begin{array}{l}\text { Down } \\
\text { regulation }\end{array}$ & Vesicles & $\begin{array}{l}\text { Transform growth factor beta receptor binding, } \\
\text { molecular function and protein binding }\end{array}$ \\
\hline
\end{tabular}




\begin{tabular}{|c|c|c|c|}
\hline Proteins & Regulation & Position & Functions \\
\hline RHOA & $\begin{array}{l}\text { Down } \\
\text { regulation }\end{array}$ & Cell membrane & $\begin{array}{l}\text { Regulate a signal transduction pathway, } \\
\text { microtubule-dependent signal }\end{array}$ \\
\hline PRDX1 & $\begin{array}{l}\text { Down } \\
\text { regulation }\end{array}$ & $\begin{array}{l}\text { Cytoplasm, } \\
\text { Melanosome }\end{array}$ & $\begin{array}{l}\text { Participate in cell protection against oxidative } \\
\text { stress }\end{array}$ \\
\hline G6PD & $\begin{array}{l}\text { Down } \\
\text { regulation }\end{array}$ & $\begin{array}{l}\text { Cytosol, } \\
\text { Microtubule } \\
\text { organizing center, } \\
\text { Vesicles }\end{array}$ & $\begin{array}{l}\text { Provide reducing power and pentose phosphates } \\
\text { for fatty acid and nucleic acid synthesis }\end{array}$ \\
\hline BLMH & $\begin{array}{l}\text { Down } \\
\text { regulation }\end{array}$ & Cytoplasm & $\begin{array}{l}\text { Protect normal and malignant cells from BLM } \\
\text { toxicity }\end{array}$ \\
\hline TALD01 & $\begin{array}{l}\text { Down } \\
\text { regulation }\end{array}$ & Cytoplasm & $\begin{array}{l}\text { Balance of metabolites in the pentose-phosphate } \\
\text { pathway }\end{array}$ \\
\hline DCD & $\begin{array}{l}\text { Down } \\
\text { regulation }\end{array}$ & Extracellular & Antimicrobial activity and proteolytic activity \\
\hline PCSK9 & $\begin{array}{l}\text { Down } \\
\text { regulation }\end{array}$ & Cytoplasm & $\begin{array}{l}\text { Crucial player in the regulation of plasma } \\
\text { cholesterol homeostasis and regulate neuronal } \\
\text { apoptosis }\end{array}$ \\
\hline GAPDH & $\begin{array}{l}\text { Down } \\
\text { regulation }\end{array}$ & $\begin{array}{l}\text { Cytoplasm, } \\
\text { Cytosol, Nucleus }\end{array}$ & $\begin{array}{l}\text { Participate in nuclear events including } \\
\text { transcription, RNA transport, DNA replication and } \\
\text { apoptosis }\end{array}$ \\
\hline
\end{tabular}

The differentially expressed proteins were selected for further analysis. According to the cellular component analysis, the differentially expressed proteins were enriched in extracellular exosomes, followed by cytosol and extracellular spaces (Fig. 2C). These differentially expressed proteins may act on AIS by participating in biological processes such as cell-cell adhesion, proteolysis, and the Fc-epsilon receptor signaling pathway (Fig. 2D). In the AIS patients, some proteins, such as FN1, were upregulated and others, such as VDAC1, RhoA and AHNAK, were downregulated. The FN1, VDAC1, RhoA and AHNAK proteins interacted to influence the development of AIS (Fig. 2E). These results suggest that the plasma exosomal proteins FN1, VDAC1, RhoA and AHNAK are likely biomarkers of AIS.

\section{The RhoA and VDAC1 proteins were downregulated in the AlS patients}

To further determine whether the proteins were significantly different in the AIS patients, we selected FN1, RhoA, VDAC1 and AHNAK for verification in vitro. Proteomic analysis confirmed that the differentially expressed proteins in the AIS and control groups were mostly distributed in the extracellular exosomes; thus, the characteristics and target proteins of the plasma exosomes were further verified and analyzed in this study.

Extracellular vehicles (EVs) isolated from the plasma of the AIS patients and the controls were identified by using transmission electron microscopy and particle size detection (Fig. 3A, B). Additionally, western blotting was performed to detect the expression of the exosomal marker CD63 and the endoplasmic 
reticulum-specific marker calnexin but not the transmembrane protein TSG101 (Fig. 3C). Flow cytometric analysis of the exosomal markers CD63 and CD81 confirmed that the isolated EVs were purified exosomes (Fig. 3D).

To determine whether the RhoA, VDAC1, FN1 and AHNAK protein levels differed between the AIS and control groups, we performed western blot analyses of the two groups. The results showed that the RhoA and VDAC1 protein levels in the AIS group were significantly lower than those in the control group, consistent with the MS results (Fig. 3F). However, the FN1 protein was downregulated in the AIS patients (Fig. 3E), contrary to the MS results. After analyzing the grayscale values, we found that the RhoA protein expression in the controls was greater than twice that of the AIS patients. The AHNAK protein did not differ between the AIS patients and the controls. Taken together, the results showed that RhoA and VDAC1 may play a vital role in AIS patients.

\section{The RhoA and VDAC1 were associated with the severity in the AIS patients}

To determine whether RhoA and VDAC1 expression correlates with the severity of AIS patients, we further analyzed the clinical characteristics and protein expression. Comparing the patients' baseline values, we observed that the Cobb angle had a significant association with the RhoA and VDAC1 proteins. The Cobb angle is used for quantitative assessment of the lateral curvature of the spine, representing the severity of AIS. After Pearson analysis, the results showed that the Cobb angle was negatively correlated with the RhoA and VDAC1 proteins (Fig. 4), and the formulas were shown as below:

$$
\begin{aligned}
& \mathrm{Y}_{\mathrm{RHOA}}=-37.71 * \mathrm{X}_{\mathrm{cobb}}+7309\left(\mathrm{R}^{2}=0.5174\right) \\
& \mathrm{Y}_{\mathrm{VDACl}}=-20.27 * \mathrm{X}_{\text {cobb }}+2546\left(\mathrm{R}^{2}=0.5465\right)
\end{aligned}
$$

\section{The related pathways were involved in the RhoA and VDAC1 proteins in the AIS patients}

To explore how the RhoA and VDAC1 proteins are involved in AIS, we next performed an analysis of the KEGG signaling pathways for Homo sapiens (human). The RhoA protein influences AIS primarily through the chemokine signaling pathway, platelet activation and CAMP signaling pathway, and the VDAC1 protein is a key factor that participates in the necroptosis pathway, acting on the development of AIS. These data showed that the RhoA and VDAC1 proteins are likely predictors of AIS. The pathway networks are shown (Fig. 5-6).

\section{Discussion}

This is the first report confirming the role of exosomes in AIS. We identified the differentially expressed proteins VDAC1, RhoA, FN1 and AHNAK in AIS, and VDAC1 and RhoA were downregulated, which is 
related to the severity and progression of the disease. Exosomes are likely potential biomarkers and predictors of AIS.

Our study first screened the differentially expressed proteins in the total plasma proteins, and the differentially expressed proteins were concentrated in the exosomes. To further identify biomarkers, we chose to verify the proteins in the exosomes. The results demonstrated that the RhoA and VDAC1 proteins were downregulated in AIS, consistent with the MS data. RhoA is an important regulator of platelet function and development ${ }^{[16]}$. RhoA directs cytoskeletal reorganization to promote shape changes and particle release during hemostasis, activating ${ }^{[16]}$ platelets and the signaling pathways of damaged vessel walls. Previous studies have confirmed the elevated levels of calcium and phosphorus in the platelets from AIS patients ${ }^{[17]}$, and the level of platelet calmodulin is a predictor of progression of the curve ${ }^{[18]}$, and some proteins over or under expressed by AIS Lenke type 5 patients were involved in the blood coagulation pathway ${ }^{[21]}$. In the platelet-skeleton hypothesis, platelet activation is thought to be accompanied by changes in calmodulin in the dilated vessels of AIS, which are related vertebral deformation, while activated platelets release growth factors in the blood vessels of the near-growth plate, stimulating the development of the vertebral endplate after mechanical injury and affecting the progression of $\mathrm{AIS}^{[19]}$. Therefore, we believe that RhoA affected the scoliosis progression of AIS by regulating platelet function. As a key factor in mitochondrial apoptosis, VDAC1 is involved in the release of mitochondrial proapoptotic proteins into the cytosol, and overexpression and dysregulation of this pathway induce apoptosis and other related diseases. The asymmetry of the paravertebral muscles has been observed in AIS. We hypothesize that under different dynamic cell conditions, the difference between activated chondrocyte proliferation and apoptosis in the vertebral body and the convex side growth plate leads to lateral curvature and rotation. TheVDAC1 protein may influence the growth and imbalance of muscles and bones by promoting the apoptosis and proliferation of chondrocytes, resulting in scoliosis. This result is consistent with the previous study, which given that vitamin $\mathrm{D}$ binding protein (DBP) is associated with bone metabolism and play an important role in the pathogenesis of AIS or disease severity ${ }^{[21]}$.

However, the results for FN1 were inconsistent in MS and western blotting. Most likely, total plasma proteins were mixed with other components detected by MS, but western blotting focused only on the exosomes. Previous studies have shown that FN is increased in AIS patients with Lenke type 5 curvature [21]. Therefore, more studies are needed to demonstrate the role of FN1 in AIS in the future, but we believe that exosomes are useful in our study because these particle achieve intercellular material transfer and information exchange and are involved in regulating cellular physiological functions and certain pathological processes ${ }^{[20]}$.

This study has some limitations. First, the validation of the biomarkers was performed in a small cohort of patients, and only 18 subjects including 10 patients with primary moderate to severe AIS were enrolled. Second, considering that AIS is more common among females than males, this study needed more female subjects. Third, the selection of the target proteins may be biased. Previous studies have reported 
that the VDAC1, RhoA, FN1 and AHNAK proteins are related to AIS. Moreover, other related differentially expressed proteins should be studied. Exosomes should be examined in animals in the future.

\section{Conclusions}

In this study, the first to examine exosomes in AIS, we demonstrated that exosomes are potential biomarkers of AIS, and RhOA and VDAC1, as target proteins in AIS, were downregulated, predicting the severity of AIS. Therefore, exosomes can probably be used for the early diagnosis of AIS.

\section{Abbreviations}

Adolescent idiopathic scoliosis (AIS); Rhodopsin A (RhoA); voltage-dependent anion-selective channel 1 (VDAC1); fibronectin 1 (FN1); mass spectrometry (MS); Scoliosis Research Society (SRS); Ingenuity Pathway Analysis (IPA); extracellular vehicles (EVs); vitamin D binding protein (DBP).

\section{Declarations}

\section{Ethics approval and consent to participate}

The study was approved by the Ethics Committee of Xinhua Hospital Affiliated to Shanghai Jiao Tong University School of Medicine and written informed consent was obtained from each patient.

\section{Consent to publish}

The authors have received written consent from participants to publish individual patient data.

\section{Availability of data and materials}

The datasets supporting the conclusions of this article are included within the article.

\section{Competing interests}

The authors declare that the research was conducted in the absence of any commercial or financial relationships that could be construed as a potential conflict of interest.

\section{Funding}

This study was supported by General Program of National Natural Science Foundation of China (81972030), Advanced and Appropriate Technology Promotion Projects of Shanghai Municipal Health Commission (2019SY021) and Training Program for Clinical Research of Xinhua Hospital Affiliated to 
Shanghai Jiao Tong University School of Medicine (17CSK02). The funders had no role in the design and conduct of the study; collection, management, analysis, and interpretation of the data; preparation, review, or approval of the manuscript; and decision to submit the manuscript for publication.

\section{Authors' Contributions}

QD, NS and XZ participated in the study design, data collection, analysis of data and preparation of the manuscript.LM , NC, XL and YY carried out the experimental work and the data collection. $\mathrm{HL}, \mathrm{MC}, \mathrm{JL}$ participated in the interpretation of data and drafted the manuscript. QD critically revised the manuscript. All authors read and approved the final manuscript.

\section{Acknowledgments}

We thank all subjects for providing the venous blood and the Chinese Academy of Sciences for analyzing the data, and all people who had contributed to research.

\section{References}

1. Zhang Y, Gu Z, Qiu G. The association study of calmodulin 1 gene polymorphisms with susceptibility to adolescent idiopathic scoliosis. Biomed Res Int. 2014;2014:168106.

2. Fong DY, Cheung KM, Wong YW, Wan YY, Lee CF, Lam TP, et al. A population-based cohort study of 394,401 children followed for 10 years exhibits sustained effectiveness of scoliosis screening. Spine J. 2015;15(5):825-33.

3. Newton Ede MM, Jones SW. Adolescent idiopathic scoliosis: evidence for intrinsic factors driving aetiology and progression. Int Orthop. 2016;40(10):2075-80.

4. Kumar A, Kumar S, Sharma V, Srivastava RN, Gupta AK, Parihar A, Verma V, Kumar D. Efficacy of Task Oriented Exercise Program Based on Ergonomics on Cobb's Angle and Pulmonary Function Improvement in Adolescent Idiopathic Scoliosis- A Randomized Control Trial. J Clin Diagn Res. 2017;11(8):YC01-4.

5. Lee JZ, Lam DJ, Lim KB. Late presentation in adolescent idiopathic scoliosis: who, why, and how often? J Pediatr Orthop B. 2014;23(1):6-14.

6. Sun ZJ, Jia HM, Qiu GX, Zhou C, Guo S, Zhang JG, et al. Identification of candidate diagnostic biomarkers for adolescent idiopathic scoliosis using UPLC/QTOF-MS analysis: a first report of lipid metabolism profiles. Sci Rep. 2016;6:22274.

7. Nikolova S, Yablanski V, Vlaev E, Getova G, Atanasov V, Stokov L, Savov AS, Kremensky IM. In Search of Biomarkers for Idiopathic Scoliosis: Leptin and BMP4 Functional Polymorphisms. J Biomark. 2015;2015:425310. 
8. Muller L, Hong CS, Stolz DB, Watkins SC, Whiteside TL. Isolation of biologically-active exosomes from human plasma. J Immunol Methods. 2014;411:55-65.

9. Faict S, Muller J, De Veirman K, De Bruyne E, Maes K, Vrancken L, et al. Exosomes play a role in multiple myeloma bone disease and tumor development by targeting osteoclasts and osteoblasts. Blood Cancer J. 2018;8(11):105.

10. Zhang Y, Cai F, Liu J, Chang H, Liu L, Yang A, Liu X. Transfer RNA-derived fragments as potential exosome tRNA-derived fragment biomarkers for osteoporosis. Int J Rheum Dis. 2018;21(9):1659-69.

11. Jerez S, Araya H, Thaler R, Charlesworth MC, López-Solís R, Kalergis AM, et al. Proteomic Analysis of Exosomes and Exosome-Free Conditioned Media From Human Osteosarcoma Cell Lines Reveals Secretion of Proteins Related to Tumor Progression. J Cell Biochem. 2017;118(2):351-60.

12. Colletti M, Petretto A, Galardi A, Di Paolo V, Tomao L, Lavarello C, et al. Proteomic Analysis of Neuroblastoma-Derived Exosomes: New Insights into a Metastatic Signature. Proteomics. 2017;17:23-4.

13. Emanueli C, Shearn Al, Laftah A, Fiorentino F, Reeves BC, Beltrami C, et al. Coronary Artery-BypassGraft Surgery Increases the Plasma Concentration of Exosomes Carrying a Cargo of Cardiac MicroRNAs: An Example of Exosome Trafficking Out of the Human Heart with Potential for Cardiac Biomarker Discovery. PLoS One. 2016;11(4):e0154274.

14. Li Y, Jin D, Xie W, Wen L, Chen W, Xu J, et al. Mesenchymal Stem Cells-Derived Exosomes: A Possible Therapeutic Strategy for Osteoporosis. Curr Stem Cell Res Ther. 2018;13(5):362-8.

15. Aslan JE, Baker SM, Loren CP, Haley KM, Itakura A, Pang J, et al. The PAK system links Rho GTPase signaling to thrombin-mediated platelet activation. Am J Physiol Cell Physiol. 2013;305(5):C519-28.

16. Akbar H, Duan X, Saleem S, Davis AK, Zheng Y. RhoA and Rac1 GTPases Differentially Regulate Agonist-Receptor Mediated Reactive Oxygen Species Generation in Platelets. PLoS One. 2016;11(9):e0163227.

17. Goździalska A, Jaśkiewicz J, Knapik-Czajka M, Drąg J, Gawlik M, Cieśla M, et al. Association of Calcium and Phosphate Balance, Vitamin D, PTH, and Calcitonin in Patients With Adolescent Idiopathic Scoliosis. Spine (Phila Pa 1976). 2016;41(8):693-7.

18. Zhao D, Qiu GX, Wang YP, Zhang JG, Shen JX, Wu ZH, Wang H. Association of calmodulin1 gene polymorphisms with susceptibility to adolescent idiopathic scoliosis. Orthop Surg. 2009;1(1):58-65.

19. Burwell RG, Dangerfield PH. Pathogenesis of progressive adolescent idiopathic scoliosis. Platelet activation and vascular biology in immature vertebrae: an alternative molecular hypothesis. Acta Orthop Belg. 2006;72(3):247-60.

20. Beit-Yannai E, Tabak S, Stamer WD. Physical exosome:exosome interactions. J Cell Mol Med. 2018;22(3):2001-6.

21. Makino H, Seki S, Kitajima I, Motomura H, Nogami M, Yahara Y, Ejiri N, Kimura T. Differential proteome analysis in adolescent idiopathic scoliosis patients with thoracolumbar/lumbar curvatures. BMC Musculoskelet Disord. 2019;20(1):247. 


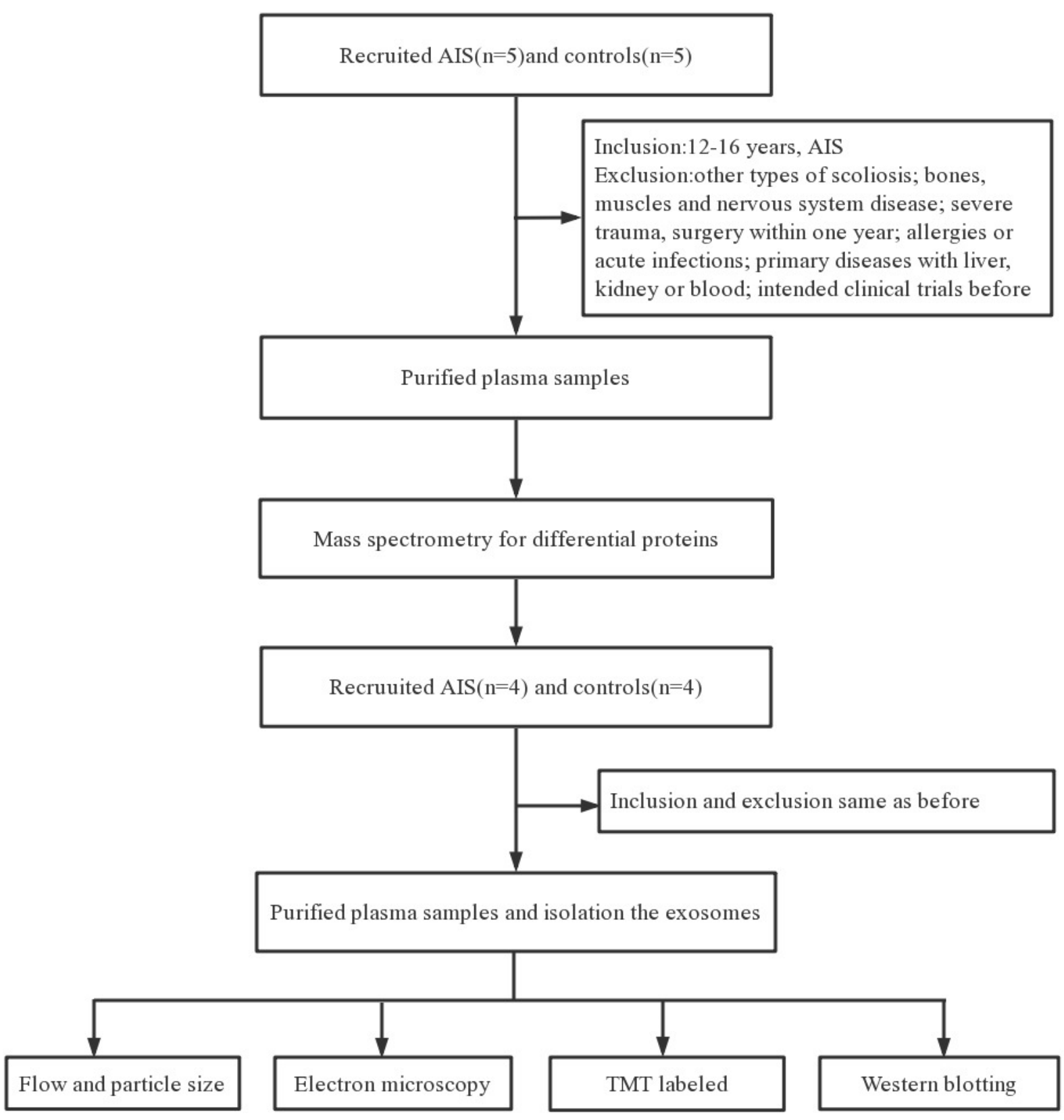

\section{Figure 1}

Study enrollment and study processes. 

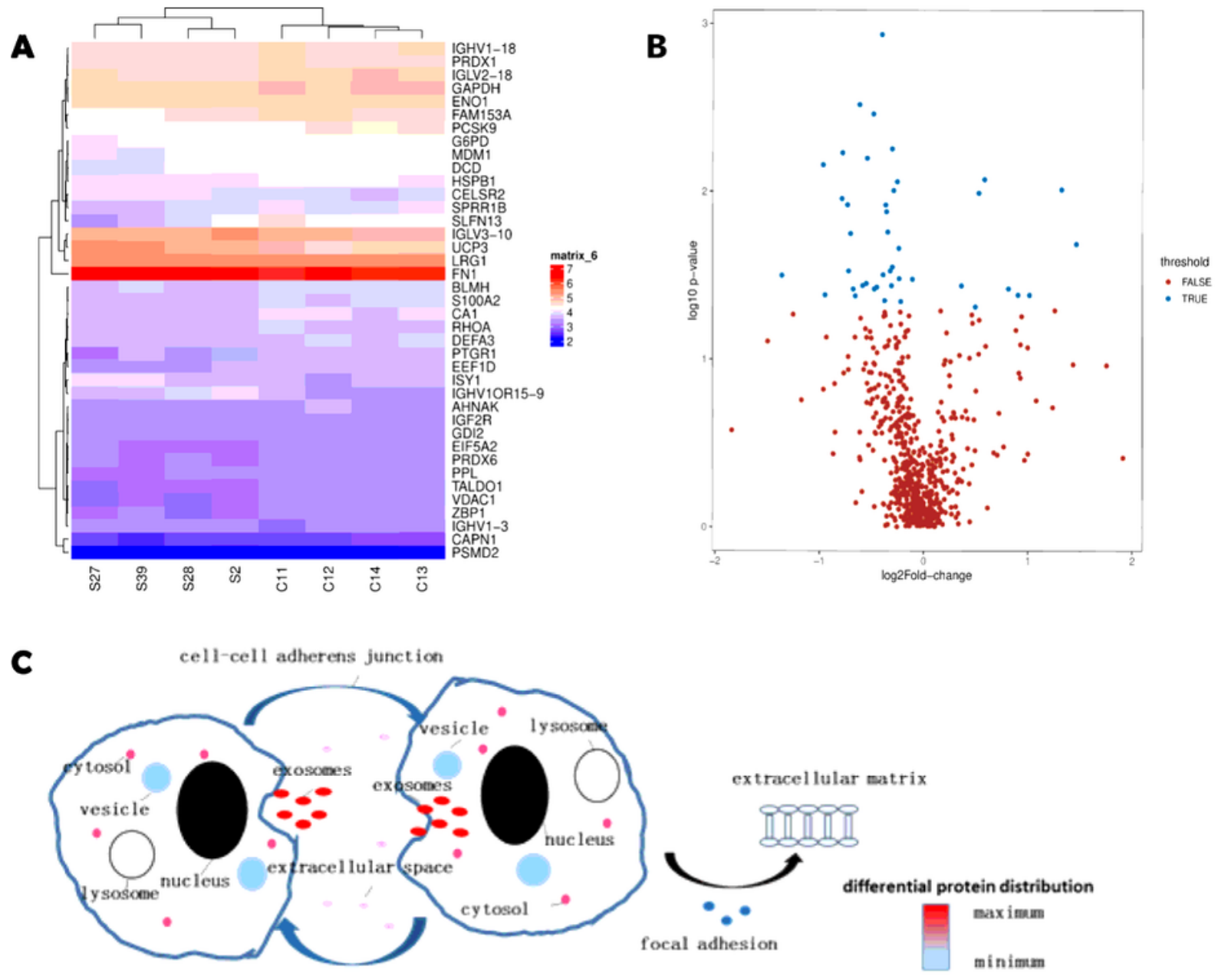

D

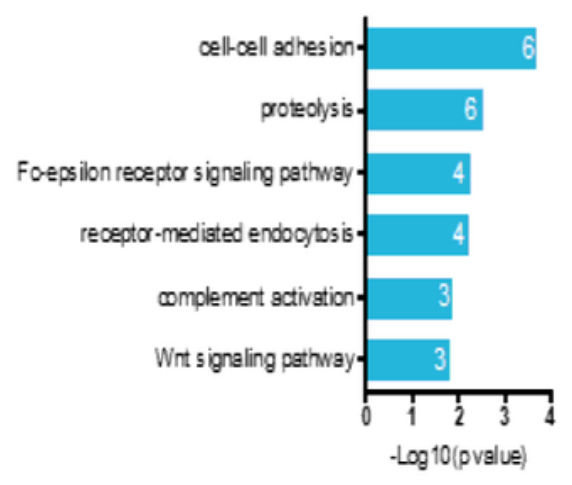

E

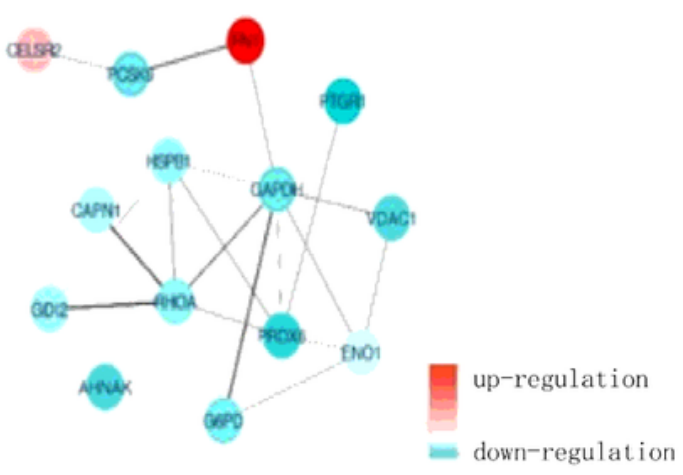

\section{Figure 2}

Candidate proteins validated from plasma exosomes. (A) Hierarchical clustering analysis. (B) Volcano plots analysis. (C) Cellular component. (D) Biological process. (E) Differential protein interaction network map. 
A

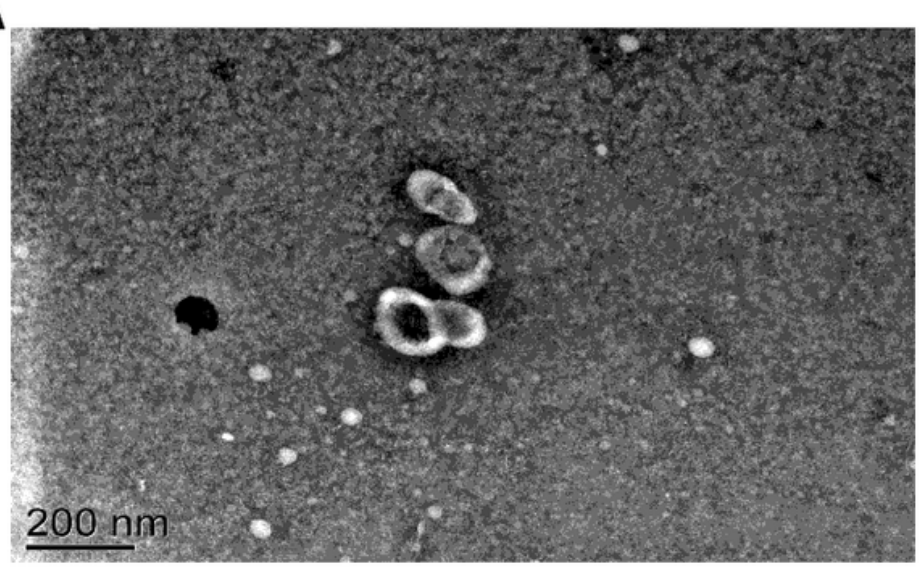

B

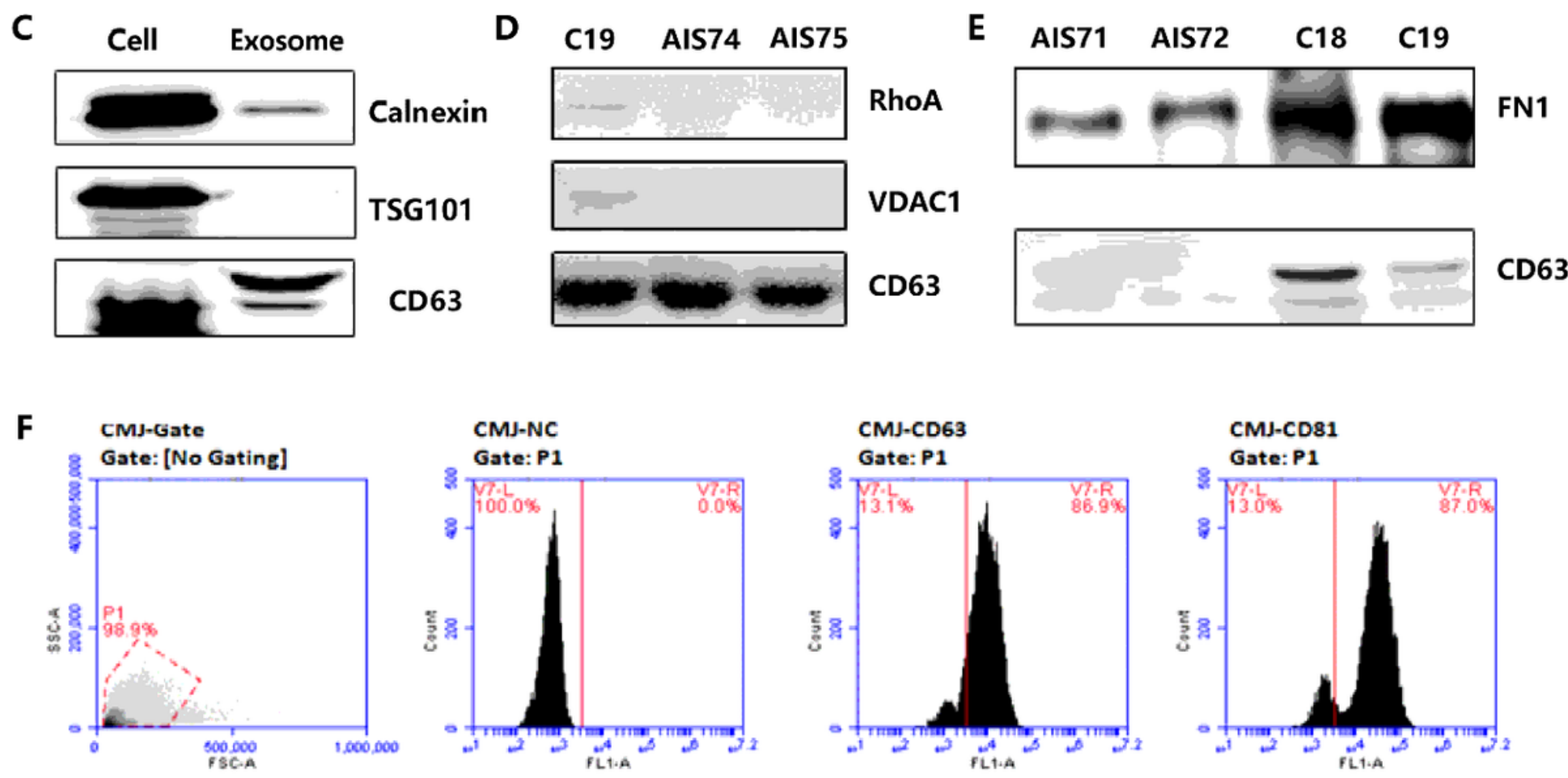

Figure 3

(A) Transmission electron microscope. (B) Particle size. (C) Western blot for exosomal marker. (D) Western blot for RhoA and VDAC1 proteins. (E) Western blot for FN1 proteins. (F) Flow cytometry analysis. 


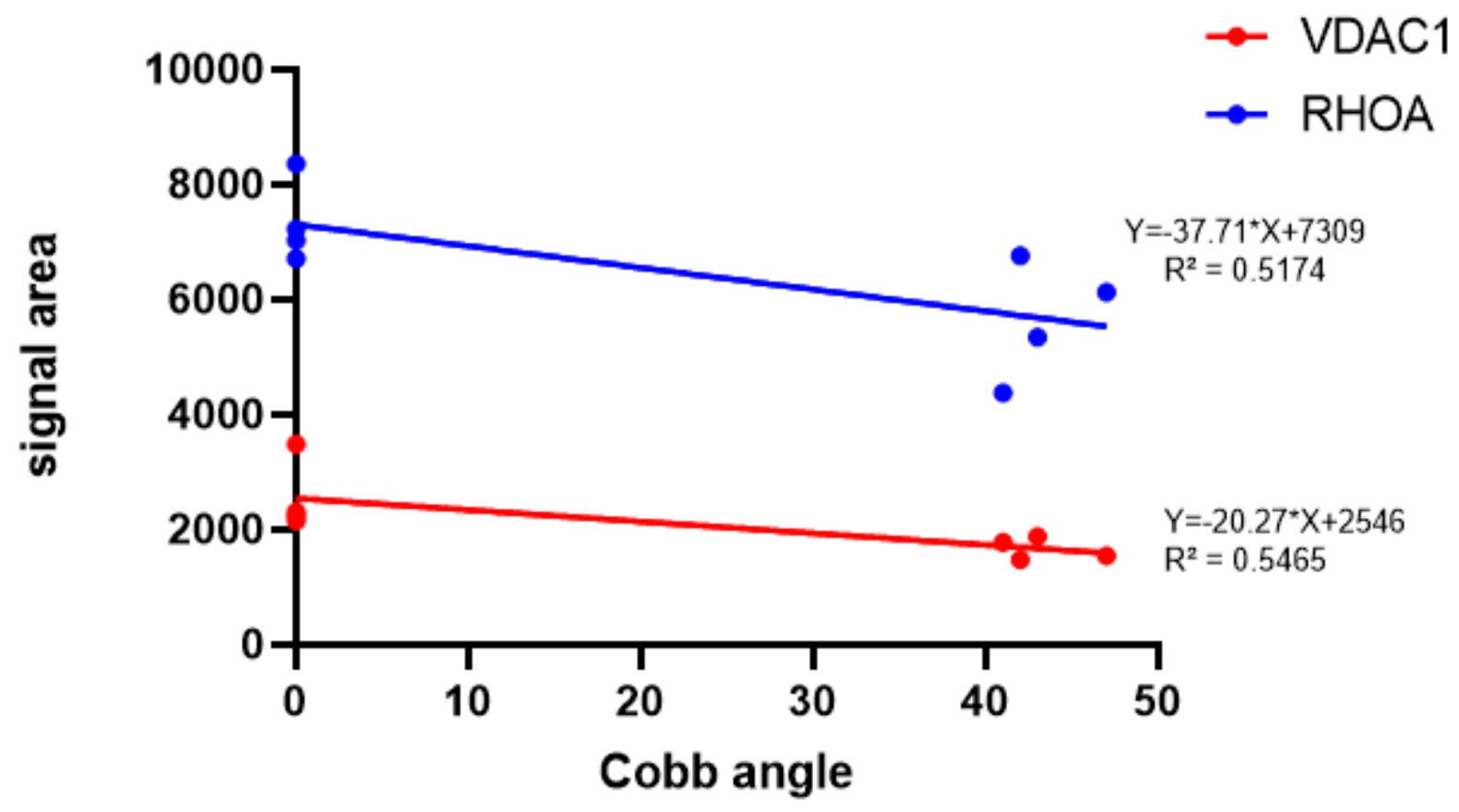

Figure 4

Pearson analysis of VDAC1 and RhoA between normal and AIS. 


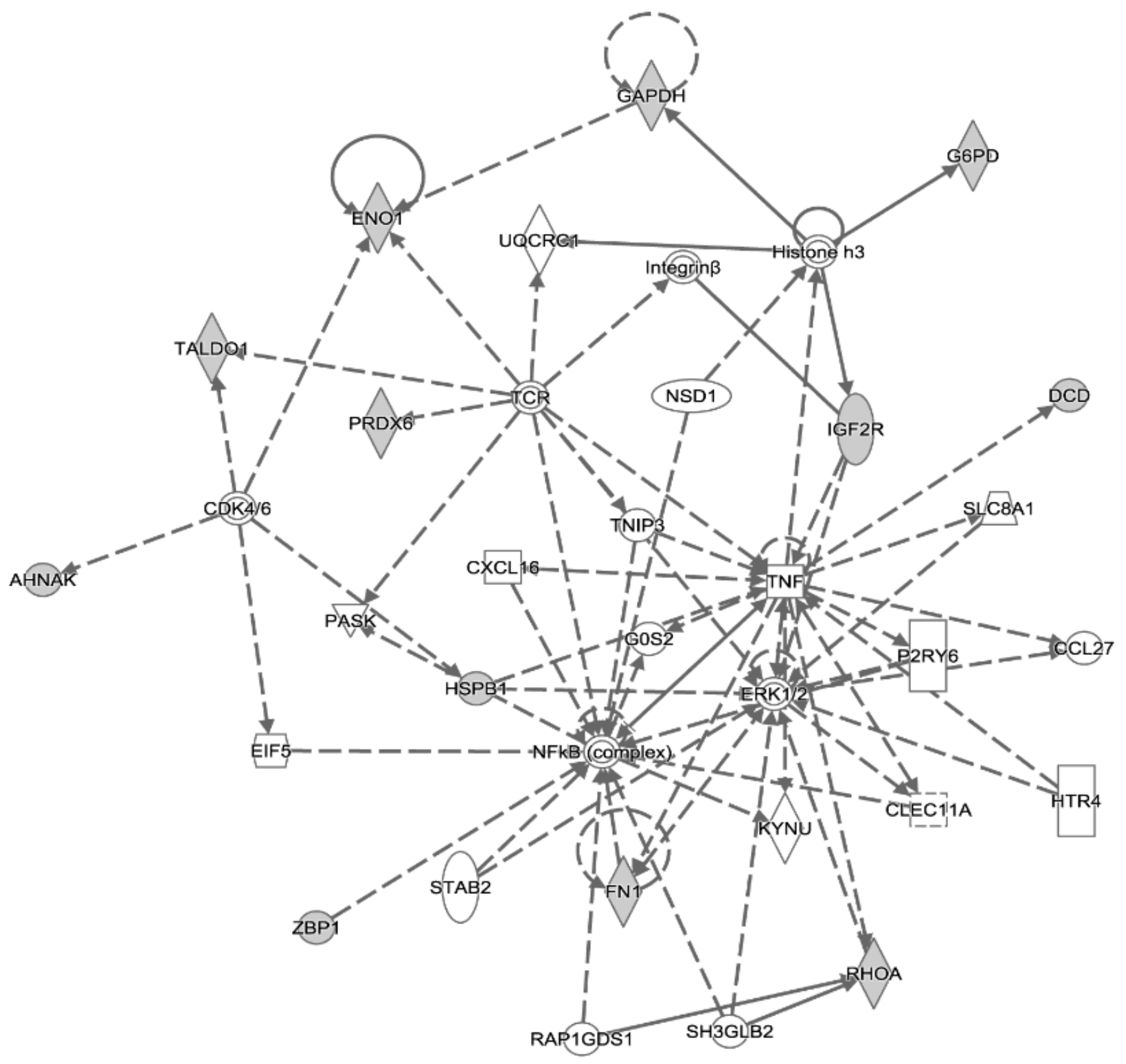

Figure 5

The predicted interactions in the differentially expressed genes related to RhoA, AHNAK and FN1 in the AIS patients. 


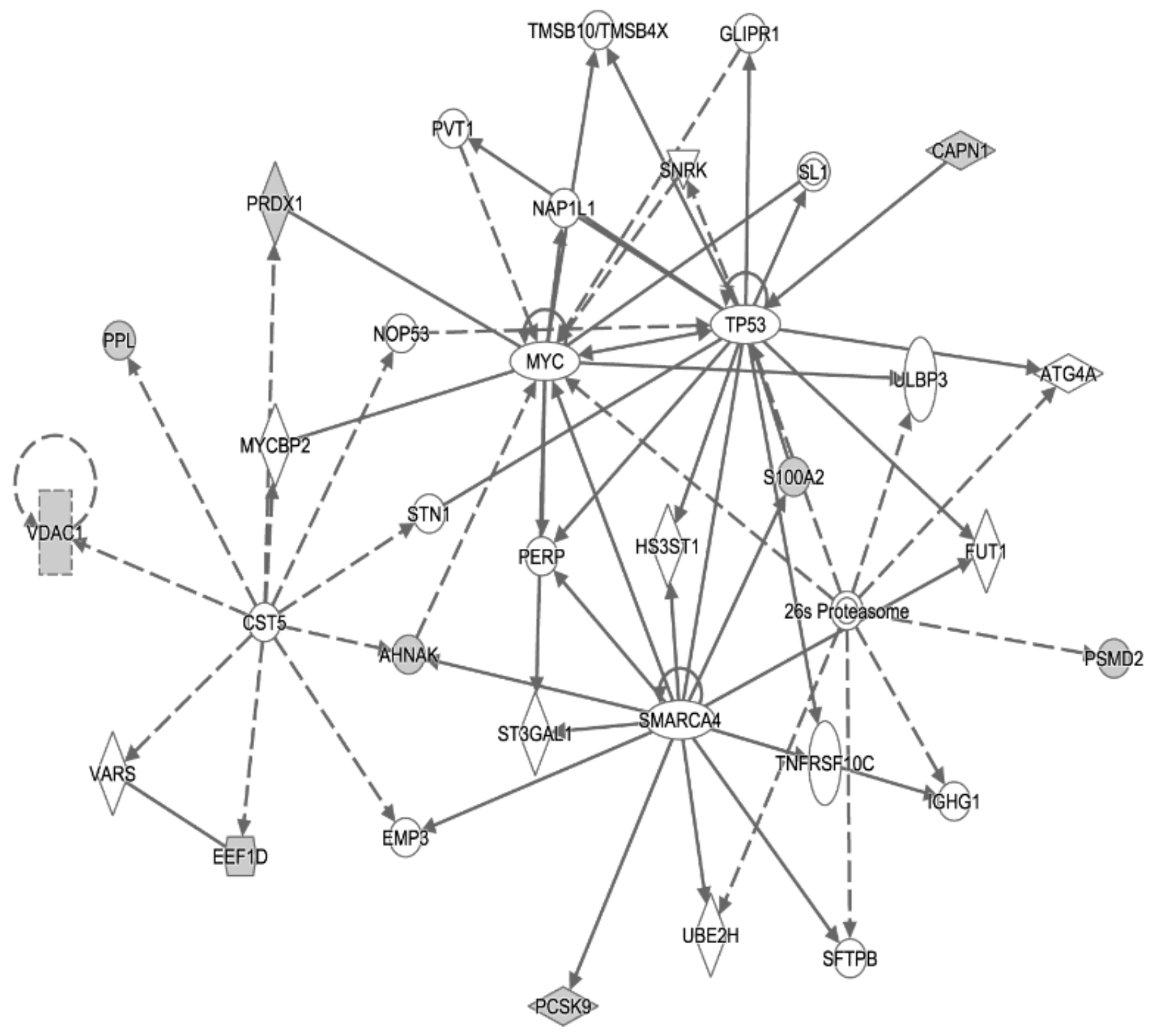

Figure 6

The predicted interactions in the differentially expressed genes related toVDAC1 and AHNAK in the AIS patients. 